\title{
A perda como um ganho: luto artístico em Sasha Waltz
}

\author{
ANABELA MENDES
}

The most recent presentation (2017) in Lisbon of Sasha Waltz \& Guests with the choreography Kreatur recovers the social and political horizon of previous works. It happens through a deep understanding of what we are as species - something we seem always to forget and distort, due to not considering our inner affinities. We lack the patience and wisdom to bring the art of the potter to the art of the dancer who, in order to reach the new and the unsuspecting, makes life an intimate ordeal to which it offers breath, gesture, movement. The dancer's ability comes from the recognition of the distant and hidden expression of what preceded him or her and which they insist on not detracting.

SPACIALITY AND BODY / DEAD BODY AND LIVING BODY / BODIES' CORALITY / REPETITION OUT OF REPETITION / PLEASURE AND TRAINING

A vida requer a paciência do oleiro, que, para fazer um vaso que o satisfaça, faz 200 só a treinar o gesto, a habilidade, a testar a sua ideia.

JOSÉ TOLENTINO MENDONÇA

Perguntava Michaela Schlagenwerth a Sasha Waltz, em 2008, e não sem alguma perplexidade, o que estaria na origem do denso, abstracto, duro e simultaneamente frágil percurso dos trabalhos da coreógrafa, quando da sua permanência na Schaubühne (1999-2004), altura em que fora directora artística dessa estrutura cultural com Jochen Sandig, Thomas Ostermeier e Jens Hillje?

O que terá notado a crítica de dança alemã nas produções desse período, nomeadamente em Körper (Corpos), $S$ e noBody (nenhumCorpo/ /ninguém), uma trilogia dedicada, entre outros temas, à questionação 
entre corpo e espaço? Insideout e Impromptus integrariam ainda as criações dessa época.

A existirem razões que sustentem e tornem mais perceptível esta mudança na concepção estética e ontológica da obra da coreógrafa alemã, podemos considerar que uma delas terá sido, não duvidemos, a possibilidade de Waltz ter conseguido experimentar durante um longo período com os seus bailarinos as dimensões de um espaço físico descomunal quando comparado a anteriores lugares de criação.

A descoberta e o aproveitamento das novas funcionalidades do lugar, que do ponto de vista de Waltz (Waltz, 2008: 58) viriam a interferir na sua concepção coreográfica daí em diante, mesmo em espaços outros como museus, plataformas ao ar livre, anfiteatros, inusitados lugares de habitabilidade imprevista (a tina cheia de água em material transparente onde se dança Dido e Aeneas), proporcionam um consciente acentuar das relações entre corpos e o seu existir e a dimensão e proporcionalidade da área de trabalho.

As coreografias de Waltz, as correspondentes cenografias (Thomas Schenk, Heike Schuppelius, Sasha Waltz) disputam a verticalidade e a profundidade de superfícies até então inexploradas. Constata-se assim que a reciprocidade de acção entre corpo e espaço não resulta de uma simples junção das partes, mas antes se manifesta para lá do deslocamento do corpo e sua energia motriz, i. e., como um movimento que é reflexo do funcionamento do sistema nervoso central e periférico, mas é também um exercício de consciência e resistência. $E$ a condição de aceitar correr riscos no desenvolvimento coreográfico individual e/ou colectivo, aspecto que as concepções de Waltz consideram sempre de forma meticulosa e a favor dos seus bailarinos ${ }^{1}$, não evita que o nosso espanto como espectadores não possa aqui ou acolá ser desapaziguado pelo hipotético perigo de desafiar o destino. Trepar a uma parede (Körper, 200o), contrariando a força da gravidade, requer que se sinta e compreenda quando é o exacto momento para que essa acção aconteça.

Um pé-direito quase a perder de vista, que os nossos olhos perseguem do chão até à grelha de luz carregada de projectores, numa assepsia que o betão enforma, eis o que orgulha a arquitectura da Schaubühne am Lehniner Platz, desde 1981, e a que Waltz e os seus artistas não foram indiferentes. Aí se inventa, a partir de então, o jogo de abrir e fechar aos 
que criam e aos que espectam aquilo que projecta como representação exterior os efeitos da mobilidade e dimensão (67,5 $\mathrm{m}$ de comprimento por $21 \mathrm{~m}$ de largura para cada uma das três salas independentes). Rasgar a área de cada uma das salas disponíveis transformando-as numa só foi a escolha da coreógrafa para a sua trilogia. ${ }^{2}$ Juntos, intérpretes e espectadores sofreram então por ser, e ainda sofrem em digressão; sofreram, e ainda sofrem, por se conhecer; continuam a resistir implacavelmente, exultantemente. Neste sentido geral se projectou o tríptico waltziano, não apenas como desenho de configuração habitável de um espaço na sua notação inscrita na linha de terra, mas também como projecção dos corpos em direcção ascendente e descendente, como se a cada bailarino fosse dada a liberdade de sondar acusticamente as paredes, que escalava através de uma estrutura em ferro oculta na penumbra, ou fosse sensível ao cheiro que delas emanava, porventura atento à rugosidade do próprio material.

Individualmente mas sobretudo nas composições de conjunto, os corpos de mulheres e homens, apenas vestidos por uma cueca de cintura meio subida e em cor de carne, construíam a partir da parede de suporte, agilizada com gradeamento em ferro (o afastamento do oculto perigo, fiel e insuspeito), uma nova parede de matéria viva. Instigados por um certo furor de serem em simultâneo parte e todo, visíveis na sua corporalidade, os bailarinos entreteciam a carne íntima e exposta ao explorarem potencialidades físicas de movimento, adaptação a exíguo e desenhado espaço, suspensão do corpo em equilíbrio instável. Aqueles corpos subiam uns por cima dos outros criando ritmos de construção e interacção diversos, em registo lento e rigoroso, formando camadas afiliadas à parede matricial, que, apesar da sua brutal imponência, mais não era do que aquele frio objecto que inicialmente os inspirara.

Seria apenas isso? Se assim fosse, haveria verdadeira troca entre corpo e espaço? A cada um as suas propriedades e características. Matéria viva versus matéria armada, o betão. A parede iluminava o espírito, intervinha na mente dos bailarinos, que não estavam impedidos de pensar metonimicamente em outras paredes, em muitas e assustadoras formas de produzir fechamento, irrespirabilidade, mortífero toque, mas também apaziguamento, protecção, harmonia. Agir sobre e com o corpo, e obviamente sobre o seu interior (não é de cirurgias que trata este 
discurso) era função da parede e de todo o espaço, praticamente esvaziado de objectos, que caracterizou a apresentação deste tríptico.

Sasha Waltz estabeleceu como prioridade na Schaubühne que o seu trabalho com os bailarinos os fizesse adquirir à vontade e segurança nos sucessivos desenhos coreográficos por ela produzidos, que gerissem o espaço pela sua exterioridade, com prazer e rigor. Lançou-lhes, porém, o repto de que o caminho a alcançar seria o da progressiva consciencialização da interioridade de cada um (a mais íntima morada do corpo) e dos intuitos que a tornariam expressiva individual e colectivamente. Deste modo pretendia a coreógrafa aproximar-se do «núcleo da Humanidade» (Waltz, 2008: 60).

$\mathrm{O}$ que quereria dizer para Waltz aceder ao essencial que nos forma $\mathrm{e}$ define? Como testemunhar através da dança o ciclo de vida e morte que nos é próprio como seres vivos? Que parte das experiências pessoais adquire interesse para uma produção artística? Que imagens se sobrepõem a outras imagens e como elas nos conduzem na descoberta das múltiplas linhas estruturantes das coreografias?

Se é verdade que Körper cruzava diversas formas de relacionar o corpo com o espaço mas também com a medicina, com a História, é a relação entre vida e morte e os seus sistemas e órgãos que se torna dominante no pensamento de Waltz, nomeadamente através do exercício interpretativo dos seus bailarinos que dão corpo ao corpo sem iludir a motivação científica, antes criando com ela o fundamento da coreografia.

Talvez deste modo se torne mais perceptível que o trabalho realizado por Waltz em noBody (2002), a última peça coreográfica do tríptico, esteja carregado de memórias afectivas e dolorosas de suprema importância.

Em discurso confessional, Waltz abre o seu coração a Michaela Schlagenwerth, no tal ano de 2008.

Um certo retraimento em noBody teve também que ver com a minha vida própria e pessoal, pelo facto de a minha mãe ter então morrido. Esta morte mudou por completo a minha perspectiva de vida. Ela aconteceu tão de repente, vinda completamente do nada. A minha mãe teve um enfarte do miocárdio, que não terá sido tratado como deve ser. Nem chegámos a saber que ela estava muito mal, de um momento para o outro 
fomos informados de que ela tinha morrido. Eu tinha com a minha mãe uma relação muito intensa, por isso a notícia foi para mim um choque incrivel. Por altura do funeral fiquei na casa de Karlsruhe durante uma semana. Logo a seguir começaram os ensaios [de noBody]. Durante todo o período de luto continuei a trabalhar e por isso a peça é como é. noBody foi o meu trabalho de luto, todas as minhas imagens, tudo o que vinha de dentro exprime a minha dor e a perda por que passei, esta peça é isso. [...] A peça com que se faz luto é também a peça que ficará no repertório como um aleijão. [idem, 65/67, tradução minha)

Coreografia múltiplas vezes revisitada, noBody deixa-se cortar e remontar sem que sentisse Waltz a capacidade de enfrentar emocionalmente e ao mesmo tempo a experiência da morte da mãe e a da vida da arte. A última peça do tríptico terá deixado marcas da mágoa, terá obrigado o cérebro a desaprender. Quantas vezes a coreógrafa terá posto à volta do pescoço aquela simbólica corda do desespero que haveria de transformar para cena, por exemplo, no fato negro e elástico, dentro do qual um corpo vivo (Juan Kruz Diaz de Garaio Esnaola) e um corpo vivo-morto (Nicola Mascia) se queriam fundir e não fundir? A etiologia da morte confunde mais do que esclarece, e impregna de emoções e reacções corporais o que nos acontece e as circunstâncias em que fazemos luto, quase sempre contra nós mesmos.

Em noBody, reencontramo-nos com a temática do corpo na sua relação potencialmente inovadora com o espaço, aspecto que atravessa toda a trilogia e que não nos cansamos de referir. Agora, porém, somos conduzidos na direcção da verticalidade da parede betonizada, convertida também numa montra de fragmentos que se conjugam como um dispositivo constituído por filas de janelões, através dos quais emerge luz-relâmpago, luz prolongada, corpos ou partes deles em movimento e em contraluz, imagens suspensas de objectos-corpo tridimensionais, pontualmente neonizadas, difusas (desenho de luz de Martin Hauk), que sinalizam talvez a anterioridade de um mundo memorial em paralelo com um acontecer em tempo real. A parede assim montada e com uma dinâmica que assenta no parcelamento e na totalidade de conjunto intervém de forma directa na coreografia em acção e que evolui sobre terra. No entanto, os tempos 
das acções ou da suspensão de acção na parede cenografada (Thomas Schenk, Sasha Waltz) são outros e imprimem no espectáculo um ritmo de deslaçamento, uma profundidade só possível de entender se considerarmos que a experiência humana se compõe de um equilíbrio entre luz e sombra. A coreografia, porém, está longe de evidenciar essa noção reguladora entre luz e ausência parcial ou total de luz.

A disposição e o desenho dos corpos são sumamente arrebatados pela música (Hans Peter Kuhn) composta para noBody, uma partitura de grande exigência em ritmo e cadência, inspirada, em particular, na figura da repetição. Trata-se de um frenético e poderoso som que inspira medo e ansiedade, que desorienta quem dança e quem escuta, que põe os corações dos bailarinos e os nossos próximos de uma frequência cardíaca superior a cem batimentos por minuto.

O contraste ou porventura a dimensão complementar entre verticalidade e horizontalidade diz respeito à condição de perda, de finitude, de desvanecimento, de desmaterialização, linhas de sentido que orientam e caracterizam a concepção de Waltz para esta obra e que os bailarinos incorporam no desenho dos seus movimentos em cena. Acompanham-nos os rostos fechados e perdidos que exprimem impossibilidade física e anímica de encontrar respostas satisfatórias para um todo indecifrável, marcado indelevelmente por uma tensão biológica e simbólica entre vida e morte. Gera-se em noBody um apelo constante, comum a muitas das peças waltzianas, à coralidade dos $\operatorname{corpos}^{3}$ que se deslocam em massa como a uma só voz, em círculos, em turbilhão, mudando de direcção e de velocidade, em voos que terminam em quedas, logo recomeçando em novos voos.

A MADEIRA E O PANO, NOSSA ÚLTIMA DOR

Desaparecemos na procura de identificação entre as partes e o conjunto de imagens visuais e acústicas que nos avassalam porque diante de nós a

3 Salienta-se aqui a função da expressão «coro de movimento», criada por Rudolf Laban, e que considera, entre outros, a sequência respiratória, o espreguiçamento, a acção de levantar e sentar, o funcionamento do estômago e dos intestinos, os batimentos cardíacos como movimentos que realizamos de forma automática, mas que podem ser consciencializados. Peso, tempo, espaço e fluência são, por exemplo, factores que contribuem para a articulação das qualidades básicas do movimento em dança e que interferem na capacidade de considerar como sem influxo da vontade aquilo que integra um comportamento e movimento do corpo. Em dança, a exploração destas constelações infinitas pode produzir um efeito de coralidade do corpo em tudo semelhante ao manifestado através da voz. Ver a propósito Ulrike Lampert, Tanzimprovisation: Geschichte, Theorie, Verfahren, Vermittlung, Bielefeld, 2007, transcrição, p. 50. 
arte teima em nos convocar para acto sacrificial. noBody. Que corpo é esse que não existe? Quem é ninguém? Dedicamo-nos a contemplar, dos corpos que não vemos, apenas cabeças, braços e pés. Impedidos de ver e escutar a corporalidade por inteiro, imaginamos o suor e outros fluidos, esquecemos se a carne oculta se entesa como acontece ao seu exterior. Vestem-se os bailarinos de madeira amarela do pescoço aos tornozelos (figurinos de Bernd Skodzig). O poder analítico e operatório não descura a opacidade e a espessura do material. As figuras em cena invocam o orgânico dentro do mecânico e vice-versa, estilizam o anacrónico do movimento grotesco, fantasmagórico, que também nos convoca para a rigidez de estátuas, bonecos e marionetas amputados de graciosidade, leveza, harmonia como preconizava Kleist. ${ }^{4}$ Ligam-se os mortos aos vivos numa lutuosa transacção.

Contrariando a tradição ancestral na espécie humana de que os corpos dos mortos se devem esconder dos vivos na sua sepultação, os bailarinos de noBody transportam-nos aos ombros, arrastam-nos pelo chão, compõem movimento.

Do céu do espaço descem, algures no tempo, cascatas de seda branca, pura e diáfana, sobre os bailarinos, cobrindo toda a área de cena. Esse dispositivo cénico transformar-se-á mais à frente num elemento fundamental da cenografia, porque elevará da superfície de chão e em direcção às alturas (que quererá isto dizer?) um corpo de mulher que à terra voltará depois de se ter confundido com o próprio pano. Mortalha? Nuvem ondulante?

Desafio de vida?

E é a esta dinamicidade que nos envolve e persegue, que em nós cria angústia, porque nos bloqueia e torna impotentes perante a representação do corpo morto que os vivos manobram entre si e com os seus corpos, com o seu hálito, com as gotas do seu suor. A estranheza de tudo aquilo que nos aparece à frente e nos é ao mesmo tempo tão familiar cria em nós um sentimento paradoxal, por vezes empático, por vezes de afastamento. Seremos capazes de tentar saltar por cima do poder analítico, vencer o medo e a sempre renovada estranheza face ao quanto a morte nos repugna e petrifica, ao mesmo tempo que exprime a natural evanescência última de todas as coisas que nos implicam? Como sentir e manifestar prazer e desejo por um objecto artístico que representa a mais 
íntima perda que a cada um de nós toca? Será que somos capazes de separar o lastro das nossas memórias pessoais daquele que subjaz ao discurso visual e sonoro, também de silêncio, que nos rodeia? Não conhecer esse discurso particular põe em causa um sentimento colectivo de compaixão?

Talvez que o caminho possa ser o de não abandonar a si próprios os sinais que a todos dizem respeito e que os corpos expressivos na sua coralidade artística produzem veiculando aquilo que está e é a morada mais íntima de cada um de nós: o seu corpo.

EM PÉ DE PÁGINA:

A recente passagem por Lisboa de Sasha Waltz \& Guests com a coreografia Kreatur recupera o horizonte social e político de anteriores obras, a partir de um profundo entendimento daquilo que somos como espécie e que sempre nos perde porque desvirtuamos as nossas afinidades interiores de que nos estamos sempre a esquecer. Falta-nos a paciência e a sabedoria de juntarmos a arte do oleiro à arte do bailarino que, para chegar ao novo e ao insuspeito, faz da vida uma íntima provação a que oferece sopro, gesto, movimento. A sua habilidade vem-lhe do reconhecimento da expressão longínqua e oculta que o precedeu e que teima em não desvirtuar.

\section{REFERÊNCIAS BIBLIOGRÁFICAS}

BUTLER, Judith, (2007), «Body: recognizable/unrecognizable - Body and “Körper” from Sasha Waltz», in Achille Lepera, Cluster Sasha Waltz, Berlim, Henschel Verlag.

EMKE, Carolin (2007), «Verwandlung als Form des Überlebens - Notizen zu den Choreographien von Sasha Waltz», in Achille Lepera, Cluster Sasha Waltz, Berlim, Henschel Verlag.

HANNAH, Dorita (2007), «Body Space: Mining the limits between architecture and dance», in Achille Lepera, Cluster Sasha Waltz, Berlim, Henschel Verlag.

KLEIST, Heinrich von (2009), Sobre o Teatro de Marionetas e outros escritos, Lisboa, Antígona.

KRAMER, Brigitte (2014), Sasha Waltz-A Portrait, Arthaus Musik (DVD).

LAMPERT, Ulrike (2007), Tanzimprovisation: Geschichte, Theorie, Verfahren, Vermittlung, Bielefeld, transcrição.

MÜLLER, Katrin Bettina (2011), KÖRPER/S/noBody, Arthaus Musik (DVD).

RIEDEL, Christiane, WALTZ, Yoreme e WEIBEL, Peter (eds.) (2014), Sasha Waltz installations, objects, performances, Kahlsruhe, Hatje Cantz.

WALt Z, Sasha (2008), Nahaufnahm Sasha Waltz. Gespräche mit Michaela, Schlagenwerth, Berlim, Alexander Verlag. 


\section{ANABELA MENDES}

É germanista e professora na Faculdade de Letras da Universidade de Lisboa. Em 2019, tornou-se investigadora independente. Desenvolve a sua actividade científica e ensaística nas áreas da Germanística, Estética e Filosofia da Arte, Ciência e Arte, Teoria e Dramaturgia Radiofónica, Artes Performativas, Viagens de Longo Curso. Realiza actualmente um projecto, com outros investigadores, dedicado ao estudo das artes no arquipélago dos Bijagós (Guiné-Bissau), intitulado Bijagós: Uma etnia de viver homeostático. 